\title{
RAFAEL BALLESTEROS: TIEMPO, INDAGACIÓN Y LENGUAJE
}

\author{
Antonio Moreno Ayora
}

En la actualidad reconocemos a Rafael Ballesteros como autor de prestigio que ha cultivado muy diferentes géneros, desde el lírico — con el que se inició en 1969 merced a su libro Las contracifras — hasta el narrativo —en el que además consiguió en 2010 el Premio Andalucía de la Crítica por su pentalogía La muerte tiene la cara azul_, pasando asimismo por el campo del ensayo — citemos, entre otras, su aportación titulada "Notas a la poesía de Vicente Núñez" —, del teatro — Jacinto, en sus diferentes entregas (la última de 2002, en ediciones Alfar), sería el mejor ejemplo_ e incluso el de la edición crítica uno de cuyos trabajos más admirados, en coautoría con Julio Neira y Francisco Ruiz Noguera, es el libro antológico sobre José Antonio Muñoz Rojas Textos poéticos (1929-2005), publicado por Cátedra en 2006.

El más nutrido de estos géneros y el que más constantemente ha recibido la creatividad del autor malagueño ha sido el de la poesía, al que quedó vinculado desde esa citada obra de 1969 y a la que siguieron otras en las posteriores décadas, como Turpa, en 1972, o Numeraria, en 1986, todo ello hasta llegar al último publicado con el título de Los dominios de la emoción (Valencia, Pre-Textos, 2003). Pero, que sepamos, de esta sustanciosa cantidad de versos expresados siempre con una admirable originalidad de lenguaje, una irrenunciable simbología y una irreemplazable emotividad, no se había intentado hasta ahora ningún volumen de conjunto que los representara y los ofreciera comentados. Por ello, el que acabamos de conocer en edición de Juan José Lanz y al cuidado de la editorial Etc. El Toro Celeste y Fundación Unicaja resultará a partir de ahora de obligada consulta e insustituible interés para lo cual adelantamos su título: Rafael Ballesteros, Poesía 1990-2010.

Digamos desde el principio que el lector de esta que es edición íntegra de todos los libros de poesía que Ballesteros ha publicado entre 1990 y 2010 cuenta por añadidura con la magnífica y prolija exégesis literaria que Juan José Lanz, editor e introductor de la obra, escribe como presentación al volumen (págs. 9-98), y verá que tiene en ella la recapitulación de veinte años de la lírica de Ballesteros, seguramente los años culminantes de su creación, dos décadas en que el poeta se abrazó a la vida y la expresó con el ritmo cambiante de cinco

\footnotetext{
1 Publicada en Antología poética, Málaga, Puerta del Mar, 1987.
} 
poemarios que son, en orden sucesivo, Testamenta, De los poderosos, Fernando de Rojas acostado sobre su propia mano (I y II), Los dominios de la emoción y Nadando por el fuego.

Del primer libro, Testamenta, se reeditan lógicamente sus respectivas doce sesiones, de similar estructura, que responden a sendos títulos —entre ellos, "Mi cama", "Los anillos de plata", "Mi tos"-que continúan un inicial canto a la palabra ("Ay, la palabra sí: la / noble manera de tocar / la realidad. [...]") y un variopinto conjunto de reflexiones y experiencias vertidas con un lenguaje por momentos apegado al decir arcaico de los clásicos y a una sintaxis en que prevalece el estilo conceptista, el uso de la elipsis y el encabalgamiento frecuente de los versos. Versos estos de Testamenta que se hacen interrogación, confesiones en el camino individual de indagar el cuerpo y el proceso de la vida, y al fin certeza de que la muerte que la ronda quiere ocultarla con sus miserias y sus goces. Y todo ello - llamamos la atención-Ballesteros lo trata con un tono ya dubitante ya asentado en el convencimiento de la experiencia, pero siempre, de continuo, aportando un léxico plagado de invenciones morfológicas y de neologismos llamativos.

Si alguna conclusión incontrovertible puede sacarse de la lectura de Testamenta es su innegable originalidad, al menos en tres planos: el del lenguaje, el de la estructura y el de los objetos poetizados. Su estilo, evidentemente, va a contrastar con el del siguiente libro De los poderosos, de 1996, pues este último aloja —en el volumen queda representado por las ocho páginas comprendidas entre la 219 y la 226- una serena prosa poética que el mismo autor califica como "epístola sobre los poderosos", en la que va a derramar experiencias que espera que no se entiendan "desde el odio, desde el desprecio, sí". Se trata, pues, de breves textos, de cartas, que si por su forma nos recuerdan por ejemplo las Cartas marruecas de Cadalso, por su relación personal —en el texto descubrimos que el viejo Crísides le habla y aconseja al joven Jacinto- tiene mucho que ver con los clásicos consejos y las reconvenciones bienintencionadas de El Conde Lucanor. Pensamiento, filosofía, conocimiento del hombre y sus quimeras, sobre todo las que inquietan la vida de los poderosos, es lo que nos allegan estas sabrosas y experienciales misivas en cuyo fondo, una vez más, vuelve a insistirse en el poder y la magia de la palabra: así, Rafael Ballesteros —igual que se dice sobre Crísides"pone toda pasión y cuido en epístolas y versos porque sigue creyendo que la palabra puede cambiar no sólo un corazón sino también el mar...".

Ya hemos adelantado que el escritor publicó a principios de 2003, en la prestigiosa editorial Pre-Textos, un nuevo poemario al que tituló Los dominios de la emoción. Es este un libro reflexivo, reconcentrado, íntimo en distintos planos y deudor en ciertos aspectos del estilo que Ballesteros ha ido forjando en su tan citada obra mayor y fundamental Jacinto, que en sucesivas entregas fue apareciendo desde 1983 hasta su última versión, la $4^{\mathrm{a}}$, de $2002^{2}$. De tal obra conserva el gusto por la indagación (es este, por cierto, el título de un poema y el de toda la primera parte del libro) y la tendencia a formarse un conocimiento lo más exacto posible de la identidad personal: ahora no es el personaje Jacinto, sino el mismo protagonista

\footnotetext{
${ }^{2}$ Acertaba plenamente Rosa Romojaro cuando, en el Diccionario de autores de Málaga y su provincia, afirmaba que "Todo el universo poético de Ballesteros está en Jacinto. Sus intereses, su ideología, su concepción de la vida, de la sociedad, del arte, de la literatura, los diversos registros de su estilo, su lengua literaria en la infinidad de sus matices, su oscuridad y su claridad".
} 
lírico, el que se pregunta repetidamente sobre quién es, representando esta una de las razones definitorias del primero de los cuatro apartados que constituyen el poemario: "Indágame. / Entre aquello que oculto / y lo que tú supones". La otra razón, igualmente primordial, es la reflexión emocionada sobre los recuerdos que el narrador ha ido acumulando tras las variadas experiencias que le ha dejado la muerte de seres cercanos: "Ella, entonces, en la muerte, ya no / era mi madre. Sólo ella". Y si lo que importa es la vida, la muerte se ve como agente que despersonaliza, aniquilador de la identidad, es la no vida, con lo que se establece un nuevo punto de contacto con los planteamientos filosóficos esbozados en Jacinto. Desde estos primeros versos, el lector descubre un libro intenso, contradictorio por cuanto está estructurado con un ritmo de lectura rápido (la construcción de cada verso exige pasar rápidamente al siguiente) que a la vez obliga al pensamiento a detenerse para penetrar las sugerencias, descifrar los significados y entender los mensajes acertadamente.

La experiencia y los recuerdos definen todo el poemario, que en la II parte amplía su contenido a temas de la realidad social y política, mostrando los deseos de compartir vivencias e intuiciones y rechazando los comportamientos líricos aislacionistas. En muchos de estos casos se entrevé el reflejo de experiencias personales de las que el poeta quiere transmitir no la anécdota sino la íntima vibración lírica que aquella le dejó: "Yo sí. Yo cada día escribiré el recuerdo. / Mi silencio dentro de aquel silencio [...]".

Es evidente que cada apartado del libro posee su propio latir, como ha admitido Ballesteros en una entrevista publicada en El País con fecha de 2 de junio de $2003^{3}$. Así, el de la III parte se aviva por el amor y por la fuerza sugerente del erotismo. De sus versos emergen recuerdos y sensaciones dejados por momentos de intimidad y de pasión, en los cuales tampoco cesa la búsqueda de la propia personalidad y del conocimiento de lo instintivo: "Yo no era realmente yo, sino el temblor / de ser el otro y más que a ti quería / lo que soñaba yo de ti y no hurgaba". Ballesteros ve el amor como una fuerza "que nos condena a nuestro exilio / y a la perseverancia de una sombra / que sí acompaña, pero que nos delata". Es decir, el amor obliga al hombre a salir de sí mismo y a buscarse en el otro ser — su sombra- que al mismo tiempo le descubre su identidad.

Nuevo latido percibimos, finalmente, en los seis poemas del último apartado, "Del desánimo y las sombras", en el que se alojan versículos más amplios que los versos precedentes. El tono familiar y directo de los mismos ("y delante poniéndome decía") se conecta con descubrimientos personales sobre la sociedad y con sentimientos de desolación y desaliento. No solo se habla del protagonista sino también de otros personajes, aunque lo que aquilata el lirismo es

3 En estas páginas de El País, Ballesteros admite que el libro está concebido con una estructura cuatripartita para reflexionar a partir de las propias experiencias acumuladas, respectivamente, sobre la más profunda identidad del protagonista lírico ("Entonces, será así: yo estoy hecho de / otro más. Y ése, el otro, no yo [...]” ), sobre sus recuerdos y vivencias conectados a la realidad social y política ("Oh, el silencio de la / noche. Yo, arriba, / arriba. De esa litera el bajo es otra celda. / ¿Quién sabe lo que un hombre solo piensa / así?”), sobre las trepidantes convulsiones íntimas del amor y del erotismo ("-Quítate las sedas de tu cuerpo, / la enagua de satén, las cintas / de tu corpiño — te gritaba - la parte / húmeda de tu algodón — y te rogaba- / pero no te quites tus sueños todavía”), y por fin sobre los sentimientos de desolación, desaliento y de la preeminencia vital de la muerte, que no solo es sombra acuciante en la 4. " parte del poemario sino también en las que la preceden ("Ay del hombre. Sus recuerdos se / esfuman con su vida. Sus palabras / se quedan en la tierra"). 
una mezcla de estrategias de refugio y defensa que dejan entrever un anecdotario de sucesos negativos que justifican el título del apartado, el más narrativo de los cuatro y, en cierto modo, el que los aglutina ${ }^{4}$. Bajo el rótulo "Al término" surgen, sin duda, los símbolos unificadores: espacio para descansar, sillas para indagar, reflexionar y disfrutar, agua para refrescar la necesaria pasión y amigos para avivar la solidaridad y compartir. Por fin, la composición de cierre "Poema de asonancias y muerte" arrastra la sombra más perenne del hombre, su preocupación más incesante, la que ya dejó eco en los primeros poemas del libro y que ahora retoma para concluirlo: "Que todo es trasmonte hueco, / sustancia accidental. / Que tras, nada"; "Ay del hombre. Sus recuerdos se / esfuman con su vida. Sus palabras / se quedan en la tierra".

En Los dominios de la emoción, con sus versos irguiéndose cálidamente por entre los límites de las páginas 246 y 322, se aprecian las constantes estilísticas que han hecho de Ballesteros un poeta original, creativo hasta los mismos límites de la creación y analista continuo de las posibilidades del lenguaje. A la fluidez del pensamiento ayudan los frecuentísimos encabalgamientos ("las olas dando, dando, contra los / esquifes") y las elipsis conceptuales ("su hijo menor, yo no lo pude"); a mantener la sorpresa y atención contribuyen tanto los arcaísmos (uno muy llamativo, vide, o el que emplea en el sintagma "cañada umbra") como la posposición pronominal ("Dame / igual como me des"), sin olvidar que estos mismos fines parece tener la traslación posicional de elementos gramaticales ("Yo daría cualquier sustancia otra"). Como ocurría en Jacinto y en otros libros anteriores (Turpa por ejemplo), Ballesteros sigue forzando las formas lingüísticas para buscar continuamente nuevos perfiles expresivos, algo que consigue con la abrumadora frecuencia de los neologismos, que unas veces afectan a la semántica del verbo ("que manúen" [“que pongan las manos']), otras a la del adjetivo ("lújuros" ['lujuriosos']), y otras revolucionan la complementación ("es tanmucho") o la morfología ("Bócame” [“Bésame’]). Todos estos rasgos demuestran que la escritura de Ballesteros no es un acto automático o impulsivo, es un acto de reflexión completo que alcanza al mensaje, a las ideas, y en igual medida al uso de las formas lingüísticas, en las que se observa tal grado de esencialidad, de originalidad y de creatividad que obliga a agudizar constantemente el intelecto para comprender en toda su amplitud la semiótica del poema 5 .

No se puede dudar, por tanto, de que para Ballesteros el lenguaje es base de creación y de indagación continua en sus posibilidades. Insistimos en que él lo demuestra tanto en las

${ }^{4}$ El autor avisa, con nitidez, de que lo importante para la persona debe ser su sentimiento (por eso vive en "los dominios de la emoción”) y la formulación lingüística que este necesita, ampliando así la misma indagación vital y romántica de Bécquer al decir: "Tu casa era tu corazón. Y tu reino / las palabras".

${ }^{5}$ El estilo literario de Ballesteros, impresionista unas veces y narrativo otras, tiene en este libro su rasgo más sobresaliente en el uso del dialogismo adaptado a los borbotones de la experiencia íntima: "Y ¿traigo a los niños? No. No. ¿Y si recuerdan?”. Otros aspectos expresivos y lingüísticos, tales como la frecuencia de neologismos, los abundantes encabalgamientos, el regusto por los pronombres enclíticos, la musicalidad tenue de las rimas internas, deben ser considerados ya constantes estilísticas de Ballesteros que, provenientes de obras anteriores (aunque aquilatados y desarrollados más que nada en Jacinto), resurgen nuevamente en Los dominios de la emoción para darle al poemario el sello personal de un poeta que está decidido a bordear los límites de la creación y a forzar el lenguaje para conseguir con él un alto grado de esencialidad y de originalidad que dé a cada poema los niveles lírico y expresivo en los cuales pese tanto la fuerza de la emoción como la capacidad del intelecto para iluminar en toda su amplitud la semiótica de lo simbolizado. 
particularidades de su léxico, al que frecuentemente aporta neologismos (“... cuanta realidad / putra y zonas hueras", pág 352 -luego en la 361 hallamos "pudro"; “... una punza en el vientre", pág. 359) y muy concretas novedades morfológicas ("Yo te daría aquellotodo...", pág. 363, o "¡Ay te fijas en su vuelo y no en la ave”, pág. 356), como en las innovaciones sintácticas que dan, muchas veces, una especial disposición al orden de los elementos ("No de lo quieto, que lo es tampoco, hablo...”, pág 348; “... Pasas las horas lentas / cuando añoras, y abrasadoras cuando", pág. 357), y todo ello por supuesto sin ignorar el valor preponderante de la elipsis, tan empleada: “¿alza el broquel si el silbo de una flecha?” (pág. 354).

$\mathrm{Su}$ deseo de conocimiento interior y de exploración filosófica de la vida — de los que encontramos una muestra reciente en su obra Fernando de Rojas acostado sobre su propia mano - lo lleva a retener formulaciones literarias del pensamiento clásico ("Lee a Epicuro. Él sabe. Nada antes, nada después") y ecos de la literatura hispana que remiten precisamente a Fernando de Rojas y a Melibea, a Carriedo y a Rubén Darío. Es este el título, fragmentado en sus dos entregas sucesivas de 1999 y de 2002, que se ofrece como poemario tercero en la actual recopilación del profesor Lanz, que sitúa tales textos (según concreción de la página 47) entre los que se engarzan en el estilo de "la prosa poética y el aforismo". Será, por cierto, el mismo poeta —ahora en la página 228 - el que adelante esta aclaración: "Yo quise imaginar que estos aforismos, que aquí publico, fueron parte de aquellos pensamientos y sentencias que, desde los más altos vuelos, le llegaron a su memoria" [la de Fernando de Rojas].

Seguramente, una de las mayores razones del interés de esta "parcial" obra completa de Ballesteros es ofrecer en sus páginas finales (325-371) un cercano poemario que se publicó —-según se especifica— "En edición bilingüe francés-español, de solo 20 ejemplares. // Les Editions de La Bastide, 2012”. Así que es evidente que con tan pocos ejemplares — sospechamos que sea fruto de una especial circunstancia o lectura- fueran también muy pocos los lectores que pudieran conocer la obra. Por ello, tenerla republicada aquí, con sus treinta y nueve poemas que la convierten en un amplio libro, es una suerte que se agradece.

Una sincera palpitación lírica asoma como primera confesión del temor a la vejez — “que no vendrán / tiempos de excitaciones y pasión, / sino de asombro y estupor"- y en consecuencia al arrastre del tiempo galopante: "toda cosa huye, se desvanece, / y la pequeña porción que queda indemne / ahúya y te abandona". Incontenible, la temática de la muerte o de finitud resuena tanto en estos versos iniciales como en los inmediatos: "Y por ser concesión de la muerte: / toda la evidencia me importuna"; "porque ya que estaba preparado / para el mundo, me queda poco mundo". Es de este modo como el libro se afianza a través de una constante meditación sobre el tiempo y las edades del hombre, pues en el poema 4 leemos: "En aquella edad el tiempo pasaba / como una dormidera, como un sedal / de láudano azul y transparente: / ¿en esos años iniciales qué importa / el correr de las noches y los días?”.

Poco a poco ese paso, rápido y fluido de la vida, se va acompasando a recuerdos, a reflexiones sobre la propia identidad y sus desdoblamientos ("Lucho por despojarme, / por dejar de ser yo absolutamente"), a experiencias diversas ya a veces alentadas por la pasión lúbrica que en la vejez se extraña ("Busco afanoso el antiguo pecado /... / Quiero hozar en aquel fango, mugir en el hueco / palpitante..."); y así hasta recalar en la propia idea de dios, visto como un atormentado más y como un ser inseguro: "Ese dios que nada sabe, ¿se humilla, pide perdón / y reza al hombre misericordioso, ser omnipotente / del cielo y de la tierra?". 
Hay una estrofa del poema n. ${ }^{\circ} 13$ "El punto y la línea" que concentra las preocupaciones líricas del poeta, quien además se define arraigado en su escritura al decir: "Yo puse casa y vida en la línea, y en ella / me deslizo como el río incesante y desigual, / busco con ansiedad lo otro, por lo siguiente indago, / sigo la hilada anhelante, apátrida siempre / y nunca ahíto, entiendo al fin que todo es parte, / accidente, cosa maleable que pasa sin retorno". A partir de aquí surgen luego, en otros lugares, preguntas sobre el transcurrir de la vida, sobre la identidad cambiante que tanto se acerca a su final "que ya tiene forma de la palabra tierra". Es leyendo muchos de estos pasajes como surge la certeza de que la poesía de Ballesteros, en buena parte de su discurso, es pregunta e indagación perennes: "y efímero en lo mucho, virtuoso sólo cuando / reflexiono, anciano sagaz".

Y junto a muchas de esas dudas resurge la sospecha de que la silenciosa muerte ronda implacable: "Entonces vi su sombra / ... / y hacia mí arrebatado, venteando mi sangre, / alzó la cimitarra con la misma fiereza / con que la hiena ríe cuando topa el despojo". Indagación y conocimiento son, pues, dos conceptos básicos para comprender la poesía de Ballesteros: indagación como necesidad para llegar a ese conocimiento tan anhelado como imposible: "Si sólo aquello que se nombra existe verdaderamente"; "Si en mi boca no cabe todo aquello que ignoro".

No declina Rafael Ballesteros en este poemario su preocupación por definir al hombre, a la poesía y a sí mismo, como constatamos en su poema (ya de los últimos) "Divertimento II", donde acaba viéndose como el hombre que se queda "mudo, lleno de asombro, diáfano y tírito como los niños ante / la vida...". Y en este trance de atender a lo humano y vital del entorno quiere observar tanto el sufrimiento ("¿Qué dolor no suma otro anterior y se encadena / a otro?") como la pasajera felicidad ("Si no alzas la alegría de tu íntimo gozo / ¿quién tuviera alegría?"). Esto sin olvidar que en todo el ejercicio de su lírica permanece siempre como un fondo neblinoso su preocupación por el tiempo que rebrota, por ejemplo, en los poemas 37 o 36, este último una disquisición temporal suscitada por el retrato sobre Ginebra dé Venci debido a Leonardo da Vinci (versos por cierto dedicados a su íntimo amigo - hoy ya fallecido- el escritor cordobés Juan Campos Reina). Como se ha anotado, la reflexión (sobre la vida, el tiempo, la muerte) es una continua indagación a la que Ballesteros nunca renuncia y con cuyo concepto concluye y refrenda este poemario — diriase que su poesía toda— en sus tres versos de cierre: “aquello que tú indagas está más hondo, más allá / de esta certeza vana, de este juego de infantes, / allá, donde si llegas, encontrarás la dicha”.

Por fin, Nadando por el fuego es un poemario en el que se van ensartando versos dialogados que dan visos de realismo y aire dramatizado al diverso contenido lírico (véase, por ejemplo, el poema $\mathrm{n}^{\circ} 28$ o el 30 ), versos en los que despunta alguna que otra frase lapidaria (como "El que dándose todo entrega poco / sólo le falta vida, no voluntad"; "Eres el pajarillo ciego que en la alta rama / se mantiene callado, a punto de caer").

Se da por sentado que el lector, antes o después de su proceso de lectura, va a atender al profundo, razonado y exhaustivo prólogo que el autor de la edición, Juan José Lanz, escribe para introducir y explicar la poesía de Rafael Ballesteros. En la línea de cuanto del ensayista y crítico conocemos, sus palabras no tienen falla ni descuido. Son imprescindibles para entender al poeta, para comprender su trayectoría y para ligar o diferenciar las etapas de su lírica. Desde el principio hallamos en sus comentarios necesarias apreciaciones formales o 
lingüísticas, como estas dos formuladas respectivamente en las páginas 10 y 12 , referentes primero a que sus modelos poéticos "abarcan desde el verso tradicional a la sentencia y la prosa poética, va(n) a enriquecer el proceso productivo de la obra ballesteriana [...]"; y luego a que "el espacio del poema se muestra como un territorio delimitado para un trasvase lingüístico del código común al código privado, en el que se produce un ámbito compartido, un espacio relacional de encuentro e intercambio entre lo privado y lo común, lo personal y lo social". Es de este modo como los comentarios de Lanz van a ir demostrando que el poema en Ballesteros acaba siendo un "espacio tensional irresoluto" desde el punto de vista expresivo y asimismo un espacio de cordialidad desde el punto de vista del contenido.

Interesantísimas las apreciaciones que en el citado prólogo se hacen al insertar la obra del poeta malagueño en las tradiciones y las estéticas de la lírica hispana, anotando con argumentos que "tradición y vanguardia se dan la mano en la poesía de Rafael Ballesteros para proponer una lectura diferente del mundo" (pág. 17). A la rima, a los recursos métricos y juegos fónicos, a la expresividad y originalidad del léxico y de la sintaxis, a la estructuración del discurso, a las técnicas compositivas que lo modelan, y a numerosos aspectos formales se refiere Juan José Lanz antes de decidirse a desmenuzar como avezado crítico cada uno de los poemarios que reúne la antología.

Queda claro en el prólogo (pág. 29) que Ballesteros va a “diseñar un nuevo modelo de escritura poética, que revoluciona, a partir de los moldes heredados, las estructuras poéticas y lingüísticas, para subvertir y cuestionar su valor dado". Y hecha esta contextualización estético-literaria dedica Lanz el resto de sus observaciones a exponer, con sabiduría y ahondamiento crítico en la materia creativa, las líneas maestras temáticas y estilísticas de cada uno de los poemarios constituyentes del conjunto. Esto hace que se comience, lógicamente, por Testamenta, libro del que ya en la primera línea advierte que "No es fácil desentrañar el complejo sentido que construye el entramado textual de Testamenta"; a pesar de lo cual él lo hace con detenimiento y acierto renovado a lo largo de diecisiete páginas, después de las cuales aborda (págs. 47 a 58) De los poderosos (1996) y Fernando de Rojas acostado sobre su propia mano (1999 y 2002). Luego reservará otras dieciséis para referirse a Los dominios de la emoción, etapa lírica que aparece caracterizada en la página 59 como "una cartografía sentimental, un mapa de la cordialidad, de la sentimentalidad, entendida no como expresión de una individualidad denotada, de un sujeto dado, sino como construcción en un espacio que ha de ser necesariamente textual y lingüístico, y, en consecuencia, social e histórico". Y tras tantas y acertadas puntualizaciones que sitúan a este libro "en un nuevo discurso poético integrador de las distintas voces que habitan la escritura ballesteriana, y avanzan el modelo que va a conformarse en Nadando por el fuego" (pág. 75), es a este último título al que se nos acerca para guiarnos una vez más por su mundo y su lenguaje.

Con la concreción y claridad que sigue inicia Juan José Lanz sus comentarios, al escribir: "A mitad de camino entre el canto elegíaco y la mirada luchadora que ansía la realización utópica, del desencanto y del enfrentamiento a todo dogmatismo, de la indagación y de la búsqueda, de la aparente desesperanza y de la fe en la humanidad, del compromiso y del canto amoroso, de la reflexión y del lirismo, en ese cruce de caminos complejo y que resume y aquilata el devenir de la obra poética de Rafael Ballesteros, se ubican los poemas de $\mathrm{Na}$ dando por el fuego, donde se sustancia lo mejor de su poesía y se aúnan las vertientes más 
diversas de su obra" (pág. 75). Y así, con este arranque crítico, expositivo y admirativo, va a continuar el ensayista analizando este libro que cierra la recopilación, sin dejar de señalar frecuentes pasajes de la lírica de Ballesteros reflejados en el texto, del que puntualiza además entre otros detalles el siguiente en que plantea (pág. 79) que "el sujeto poético de Nadando por el fuego, al subrayar la concepción elegíaca ante la conciencia de su acabamiento, adelgaza la dimensión dialógica que lo caracteriza, como reflejo de su conciencia escindida, ante la inminencia de su desaparición que marcará previamente su reintegración".

Ir leyendo la presentación de Lanz y consultando, con atención y expectativas personales, los versos que la suscitan es un modo idóneo para disfrutar y comprender este amplio conjunto de la poesía de Ballesteros. No es que este haya dejado de escribir a la altura de 2010, sino que simplemente los límites de 1990 y 2010 sirven para acotar esta segunda y trascendental etapa de su lírica. Con todo, y en el caso de quien esto ecribe, se ha preferido degustar y ahondar primero en los versos de estos cinco libros del poeta y seguir luego los vericuetos por los que transcurría el contenido y la forma que Lanz nos iba descubriendo y describiendo. Es evidente que la edición de Juan José Lanz, Profesor Titular de Literatura Española de la Universidad del País Vasco, ha despertado el interés desde que salió a la luz hace ya unos meses, como pusieron de manifiesto las páginas de la prensa periódica, de entre las que citamos la noticia de La Vanguadia (Andalucía) de fecha 30 de septiembre de 2015 con el titular "Editan un libro de Rafael Ballesteros con una selección de sus obras poéticas", o la que el periódico local Málaga Hoy, en la misma fecha, presenta como "La escritura contra el dogma". Evidentemente, este volumen unificador de la poesía de Rafael Ballestros justifica toda la atención y el seguimiento que se le puedan hacer. 